\title{
Relationship between miRNA-433 and SPP1 in the presence of fracture and traumatic brain injury
}

\author{
ZHEN HAN $^{1}$, FENG SHI ${ }^{1}$, YACHEN ${ }^{2}$, XIAOQING DONG ${ }^{1}$, BO ZHANG $^{1}$ and MENG LI $^{1}$ \\ ${ }^{1}$ First Aid Center and ${ }^{2}$ Department of Pharmacy, Jinan Zhangqiu District People's Hospital, \\ Jinan, Shandong 250200, P.R. China
}

Received April 22, 2020; Accepted March 15, 2021

DOI: $10.3892 / \mathrm{etm} .2021 .10360$

\begin{abstract}
Limb fracture combined with traumatic brain injury (TBI) is one of the most common multiple injuries and patients often suffer from severe craniocerebral injury combined with long bone fracture of the limbs. The present study examined the expression of osteopontin (SPP1) in the tibial fracture callus and heterotopic ossification tissues in craniocerebral injury and investigated its relationship with miR-433. A total of 26 patients with tibial fracture combined with brain injury were included in the TBI group, and 26 patients with simple tibial fracture were included in the control group. The patients received immobilization treatment and callus was collected during the operation. At the time of steel plate removal tissue ossification samples from patients with heterotopic ossification were collected. Peripheral blood was collected from all patients on the morning of the operation day. Expression of miR-433 and SPP1 mRNA was determined by reverse transcription-quantitative PCR and SPP1 protein expression was measured by western blotting. Dual luciferase reporter assay was used to identify the direct interaction between miR-433 and SPP1 mRNA. The human osteoblast line hFOB1.19 was transfected with agomiR-433 to overexpress miR-433 and expression of SPP1 was also examined. TBI enhanced the incidence of callus formation and heterotopic ossification in patients with fracture but did not alter fracture healing time. SPP1 mRNA and protein expression was elevated in patients who had tibial fracture in combination with craniocerebral injury in comparison with controls By contrast, expression of miR-433 was decreased in patients who had tibial fracture in combination with craniocerebral injury in comparison with controls. miR-433 regulated the expression of SPP1 mRNA and protein by directly binding to the 3'-untranslated region of SPP1 mRNA. The present study suggests that SPP1 mRNA and protein levels are increased in the callus, heterotopic
\end{abstract}

Correspondence to: Dr Meng Li, First Aid Center, Jinan Zhangqiu District People's Hospital, 220 Huiquan Road, Jinan, Shandong 250200, P.R. China

E-mail: kauddgad@163.com

Key words: miR-433, SPP1, callus, heterotopic ossification ossification tissues and plasma from patients with tibial fracture combined with brain injury in comparison with controls. This elevation may be due to the reduced expression of miR-433.

\section{Introduction}

Limb fracture combined with traumatic brain injury (TBI) is one of the most common multiple injuries and patients often suffer from severe craniocerebral injury combined with long bone fracture of the limbs (1). Early active treatment of fractures has an important impact on the prognosis of patients (2).

Brain injury not only increases the probability of heterotopic ossification, but also results in excessive callus formation and accelerated fracture healing $(3,4)$. In addition, Boes et al (5) found that the growth rate of the callus and the rate of fracture healing in rats with fracture combined with brain injury is faster than those in rats with simple fracture and that the amount of callus formed in rats with fracture combined with brain injury is greater than that in rats with only a simple fracture.

Osteopontin (SPP1), also known as early T-lymphocyte activating factor-1, is a potential proinflammatory factor related to the inflammatory response (6). SPP1 can bind to SPP1 receptors on the surface of synovial cells to induce signal transduction, which affects the adhesion and proliferation of synovial cells (7). SPP1 is overexpressed in the articular cartilage, synovial fluid and synovium of patients with osteoarthritis and its expression level is positively related to the severity of the disease $(8,9)$. The expression of SPP1 is regulated through a number of mechanisms, among which microRNAs (miRNAs/miRs) have been widely studied (10). miRNA molecules are non-encoding RNAs that have 18-22 nucleotides (11). These molecules inhibit the translation of mRNA by targeting the binding sites at the 3'-untranslated region (UTR) of mRNA (11). miR-let-7a (11) and miR-539 (12) are reported to regulate the expression of SPP1. Bioinformatics prediction suggests that miR-433 (accession no. 000014; region, homo sapiens chromosome 14; GRCh38.p13) is a potential upstream regulatory gene of SPP1 (13). miR-433 is a microRNA closely related to several human diseases. The expression of $\mathrm{miR}-433$ is increased in a fibrotic heart disease model (14) and inhibits breast cancer cell proliferation by targeting Rapla and regulating the mitogen activated protein 
kinase (MAPK) signaling pathway (15). In addition, miR-433 plays important roles in esophageal cancer and glioma $(16,17)$, but its function in the pathological process of brain injury combined with fracture has not been fully defined. It may be hypothesized that SPP1 expression is significantly increased and miR-433 expression reduced in patients with tibial fracture combined with brain injury. The negative regulation between the two may affect fracture pathology and healing process.

In the present study, the expression of SPP1 in tibial fracture callus and heterotopic ossification tissues in craniocerebral injury were examined in order to investigate the relationship between SPP1 and miR-433. The present study aimed to provide a scientific basis for the clinical diagnosis and treatment of TBI.

\section{Materials and methods}

Patients. A total of 26 patients with tibial fracture combined with brain injury received treatment at Jinan Zhangqiu District People's Hospital (China) between June 2016 and June 2018 and were included as the TBI group. In addition, 26 patients with simple tibial fracture were included as a control group. All patients received immobilization treatment and callus was collected during the operation. At the time of steel plate removal the ossified tissue samples of patients with heterotopic ossification were collected. Peripheral blood was collected from all patients on the morning of the operation day. Patients with injuries to body parts other than the brain and those diagnosed with severe infection, tumor, rheumatoid arthritis, osteoarthritis or immune-related diseases were excluded. All procedures performed in the current study were approved by the Ethics Committee of Jinan Zhangqiu District People's Hospital. Written informed consent was obtained from all patients or their families.

Reverse transcription-quantitative PCR. To examine gene expression, RT-qPCR was performed. Tissue samples (100 mg) were ground into powder in liquid nitrogen and lysed with $1 \mathrm{ml} \mathrm{TRIzol}{ }^{\circledR}$ reagent following the manufacturer's manual (Thermo Fisher Scientific, Inc.). Plasma (100 $\mu \mathrm{l}$ ) was directly lysed with $1 \mathrm{ml} \mathrm{TRIzol}{ }^{\circledR}$ reagent. Total RNA was extracted using the phenol chloroform method (18). The concentration and quality of RNA was measured using ultraviolet spectrophotometry (Nanodrop ND2000; Thermo Fisher Scientific, Inc.). cDNA was obtained by reverse transcription from $1 \mu \mathrm{g}$ RNA and stored at $-20^{\circ} \mathrm{C}$. Reverse transcription of mRNA was performed at $42^{\circ} \mathrm{C}$ for 40 min using TIANScript II cDNA First Strand Synthesis kit (Tiangen Biotech. Co., Ltd.), and reverse transcription of miRNA was carried out at $42^{\circ} \mathrm{C}$ using miRcute miRNA cDNA First Strand Synthesis Kit (Tiangen Biotech. Co., Ltd.) according to the manufacturer's instructions.

A SuperReal PreMix (SYBR Green) qRT-PCR kit (Tiangen Biotech. Co., Ltd.) was used to determine the mRNA expression level of SPP1 using $\beta$-actin as an internal reference. The sequences of the SPP1 primers were 5'-GTTATGAAACGA GTCAGCTG-3' (forward) and 5'-TTAATTGACCTCAGAAGA TG-3' (reverse). The sequences of the $\beta$-actin primers were 5'-AGCGGGAAATCGTGCGTG-3' (forward) and 5'-GAGGGT ACATGGTGGTGCC-3' (reverse). The reaction system $(20 \mu \mathrm{l})$ was composed of $10 \mu \mathrm{l}$ SYBR Premix EXTaq, $0.5 \mu 1$ upstream primer, $0.5 \mu \mathrm{l}$ downstream primer, $2 \mu \mathrm{l} \mathrm{cDNA}$ and $7 \mu \mathrm{lddH_{2 }} \mathrm{O}$.
The PCR conditions were as follows: Initial denaturation at $95^{\circ} \mathrm{C}$ for $5 \mathrm{~min} ; 30$ cycles of denaturation at $95^{\circ} \mathrm{C}$ for $30 \mathrm{sec}$ and annealing at $58^{\circ} \mathrm{C}$ for $30 \mathrm{sec}$ followed by elongation at $72^{\circ} \mathrm{C}$ for $30 \mathrm{sec}$ (iQ5; Bio-Rad Laboratories, Inc.). The $2^{-\Delta \Delta \mathrm{Cq}}$ method (19) was used to calculate the relative expression of SPP1 mRNA against $\beta$-actin. Each sample was tested in triplicate.

The expression of miR-433 was determined by miRcute miRNA RT-PCR Kit (Tiangen Biotech. Co., Ltd.), using U6 as internal reference. The sequences of the miR-433 primers were 5'-GGATCATGATGGGCTCCT-3' (forward), and 5'-CAGTGC GTGTCGTGGAGT-3' (reverse). The sequences of the U6 primers were 5'-GCTTCGGCAGCACATATACTAAAAT-3' (forward) and 5'-CGCTTCACGAATTTGCGTGTCAT-3' (reverse). The reaction system $(20 \mu \mathrm{l})$ contained $10 \mu \mathrm{l}$ qRT-PCR-Mix, $0.5 \mu \mathrm{l}$ upstream primer, $0.5 \mu \mathrm{l}$ downstream primer, $2 \mu \mathrm{l}$ cDNA and $7 \mu \mathrm{l}$ $\mathrm{ddH}_{2} \mathrm{O}$. The reaction protocol was as follows: Initial denaturation at $95^{\circ} \mathrm{C}$ for $5 \mathrm{~min} ; 40$ cycles of $95^{\circ} \mathrm{C}$ for $10 \mathrm{sec}$ and $60^{\circ} \mathrm{C}$ for $20 \mathrm{sec}$; and elongation at $72^{\circ} \mathrm{C}$ for $20 \mathrm{sec}$. The $2^{-\Delta \Delta \mathrm{Cq}}$ method (19) was used to calculate the relative expression of miR-433 against U6. Each sample was tested in triplicate.

Western blotting. To evaluate the expression of proteins western blotting was carried out. Before lysis, bone tissues (100 mg) were ground into powder, which was lysed on ice with precooled radio-immunoprecipitation assay (RIPA) lysis buffer (200 $\mu \mathrm{l}$; Beyotime Institute of Biotechnology) for $30 \mathrm{~min}$. The mixture was centrifuged at $8,000 \mathrm{x}$ g and $4^{\circ} \mathrm{C}$ for $15 \mathrm{~min}$. A Bicinchoninic acid protein concentration determination kit (RTP7102; Real-Times Biotechnology Co., Ltd.) was used to measure protein concentration in the supernatant. The samples were then mixed with $5 \mathrm{x}$ sodium dodecyl sulfate loading buffer before denaturation in a boiling water bath for $5 \mathrm{~min}$. Afterwards, the samples $(20 \mu \mathrm{g})$ were subjected to $10 \%$ sodium dodecyl sulfate-polyacrylamide gel electrophoresis at $100 \mathrm{~V}$. The resolved proteins were transferred to polyvinylidene difluoride membranes on ice $(100 \mathrm{~V}$, $2 \mathrm{~h}$ ) and blocked with 5\% skimmed milk at room temperature for $1 \mathrm{~h}$. The membranes were then incubated with rabbit anti-human SPP1 (1:1,000; cat. no. ab8448; Abcam) or $\beta$-actin (1:5,000; cat. no. ab129348; Abcam) polyclonal primary antibodies at $4^{\circ} \mathrm{C}$ overnight. After washing with phosphate-buffered saline with Tween-20 (0.1\%) 3 times, each for $15 \mathrm{~min}$, the membranes were incubated with goat anti-rabbit horseradish peroxidase-conjugated secondary antibody (1:3,000; cat. no. ab6721; Abcam) for $1 \mathrm{~h}$ at room temperature before washing with PBST 3 times, each for of $15 \mathrm{~min}$. The membrane was developed with an enhanced chemiluminescence detection kit (cat. no. ab65623; Abcam). Image lab v3.0 software (Bio-Rad Laboratories, Inc.) was used to acquire and analyze image signals. The relative quantity of SPP1 protein was measured against $\beta$-actin.

Enzyme-linked immunosorbent assay (ELISA). To measure the secretion of proteins ELISA was employed. A Human SPP1 ELISA kit (cat. no. ab100618; Abcam) was used to determine the concentration of SPP1 in the plasma according to the manufacturer's protocols. The absorbance was read by a microplate reader (Multiskan FC; Thermo Fisher Scientific, Inc.) at $450 \mathrm{~nm}$.

Bioinformatics. miRanda (http://www.microma.org/rnicroma/ home.do) was used to predict genes that might regulate SPP1 according to the guide provided by the online software. 
Dual luciferase reporter assay. To identify the direct interaction between genes a dual luciferase reporter assay was used. According to bioinformatics results, wild-type (WT; 5'-AUA UUUGUUAUUCUCUCAUGAA-3') and mutant (5'-AUA UUUGUUAUUCUCAGUACUA-3') regions of miR-433 in the 3'-UTR of the SPP1 gene were chemically synthesized in vitro. Their two ends were attached with Spe-1 and HindIII restriction sites, and then cloned into pMIR-REPORT luciferase reporter plasmids (Thermo Fisher Scientific, Inc.). Plasmids $(0.8 \mu \mathrm{g})$ with WT or mutant 3'-UTR sequences were co-transfected with agomiR-433 (100 nM; Sangon Biotech Co., Ltd.) into 293T cells (The Cell Bank of Type Culture Collection of The Chinese Academy of Sciences) at $37^{\circ} \mathrm{C}$ and under $5 \% \mathrm{CO}_{2}$ using Lipofectamine ${ }^{\circledR} 2000$ (Thermo Fisher Scientific, Inc.) according to the manufacturer's instructions. For control, 293T cells were transfected with agomiR-negative control (NC). After culture for $24 \mathrm{~h}$, the cells were lysed using a dual luciferase reporter assay kit (cat. no. E1980; Promega Corporation) according to the manufacturer's manual and luminescence intensity was measured using GloMax 20/20 luminometer (Promega Corporation). Using Renilla luminescence activity as internal reference, the luminescence values of each group of cells were measured.

Cell culture and transfection. For in vitro examination, human osteoblasts hFOB1.19 (Cell Bank of Type Culture Collection of The Chinese Academy of Sciences) were cultured in F12/DMEM medium supplemented with $10 \%$ fetal bovine serum (FBS), $100 \mathrm{IU} / \mathrm{ml}$ penicillin and $100 \mathrm{IU} / \mathrm{ml}$ streptomycin under $37^{\circ} \mathrm{C}, 5 \% \mathrm{CO}_{2}$ and $70 \%$ humidity. The cells were passaged every three days.

The day before transfection, hFOB1.19 cells $\left(3 \times 10^{5}\right)$ in the logarithmic growth phase were seeded onto 24-well plates and cultured in antibiotic-free F12/DMEM medium supplemented with $10 \%$ FBS until they reached $70 \%$ confluency. In the first vial, $0.5 \mu \mathrm{g}$ plasmids/agomiR (Sangon Biotech Co., Ltd.) was mixed with $50 \mu$ l Opti MEM (Thermo Fisher Scientific, Inc.) In the second vial, $1 \mu 1$ Lipofectamine 2000 (Thermo Fisher Scientific, Inc.) was mixed with $50 \mu 1$ OptiMEM media. After a 5 min incubation, the two vials were combined and left to incubate for an additional $20 \mathrm{~min}$ at room temperature. The mixtures were then added onto cells in respective groups. Six hours later, the medium was replaced with F12/DMEM medium containing $10 \%$ FBS. After cultured for a further $48 \mathrm{~h}$, the cells were collected for further assays.

Statistical analysis. The results were analyzed using SPSS 18.0 statistical software (SPSS, Inc.). The data are presented as the mean \pm the standard deviation. Comparisons between two groups was carried out using an unpaired Student's t-test. Comparison between more than two groups was performed by one-way analysis of variance followed by a Student-Newman-Keuls post-hoc test. $\mathrm{P}<0.05$ indicated a statistically significant difference.

\section{Results}

TBI enhances the incidence of callus formation and heterotopic ossification in patients with fracture but does not alter fracture healing time. Among the 26 patients with fracture combined with brain injury (TBI group), 16 were male and 10 were female (age range, 20-59 years; median age, 40.6 years). Among the 26 patients with simple tibial fracture (control group), 16 were male and 10 were female (age range, 18-61 years; median age, 40.2 years). None of the above patients had history of hormone or traditional Chinese medicine treatment, radiotherapy or chemotherapy. Of all the patients, 16 cases had open fractures and 36 had closed fractures. Among the patients in the TBI group, 8 cases had cerebral contusion and laceration, 12 cases had intracranial hematoma, 3 cases had diffuse axonal injury and 3 cases had brain stem injury. To evaluate the differences between the two groups, fracture healing time, the ratio of callus diameter to tibial shaft diameter and heterotopic ossification incidence were compared. The data showed that the fracture healing time in the TBI group was not different from that in the control group ( $\mathrm{P}>0.05 ; \mathrm{n}=3$; Fig. 1A). The ratios of callus diameter to tibial shaft diameter in the TBI group were significantly higher than those of the control group in both orthotopic view and lateral view ( $\mathrm{P}<0.05$ for both; $\mathrm{n}=3$ ) (Fig. $1 \mathrm{~B}$ and $\mathrm{C}$ ). In addition, heterotopic ossification incidence in the TBI group was significantly higher than that of control group $(\mathrm{P}<0.05 ; \mathrm{n}=3$; Table I). These results suggest that TBI enhances the incidence of callus formation and heterotopic ossification in patients with fractures but that it does not alter fracture healing time.

SPP1 mRNA expression is elevated in patients who have a tibial fracture in combination with craniocerebral injury in comparison with controls. The expression of SPP1 mRNA was measured using RT-qPCR. The data indicated that SPP1 mRNA levels in callus, heterotopic ossification tissues and plasma from patients in the TBI group were significantly higher than those from their respective control groups $(\mathrm{P}<0.05 ; \mathrm{n}=3$; Fig. 2A-C). The result indicates that SPP1 mRNA expression is elevated in patients who have a tibial fracture in combination with craniocerebral injury.

SPP1 protein expression is increased in patients who have a tibial fracture in combination with craniocerebral injury in comparison with controls. The protein expression levels of SPP1 were assessed using western blotting. The data indicated that SPP1 protein levels in callus, heterotopic ossification tissues and plasma from patients in the TBI group were significantly higher than those from control group $(\mathrm{P}<0.05 ; \mathrm{n}=3$; Fig. 3A-C). The result suggests that SPP1 protein expression is increased in patients who have tibial fracture in combination with craniocerebral injury.

Expression of miR-433 is reduced in patients who have a tibial fracture in combination with craniocerebral injury in comparison with controls. To examine whether the expression of miR-433 is altered in these patients, RT-qPCR was performed. The data showed that miR-433 levels in callus, heterotopic ossification tissues and plasma from patients in TBI group was significantly lower than those from the control group $(\mathrm{P}<0.05$; Fig. 4A-C; $\mathrm{n}=3)$. The result indicates that expression of miR-433 is decreased in patients who have tibial fracture in combination with craniocerebral injury.

miR-433 regulates the expression of SPP1 $m R N A$ and protein by directly binding to the 3'-UTR of SPP1 mRNA. Bioinformatics prediction is a powerful tool for the study 
A

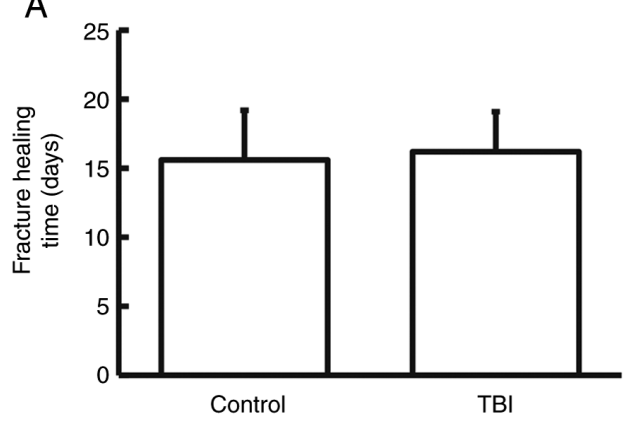

B

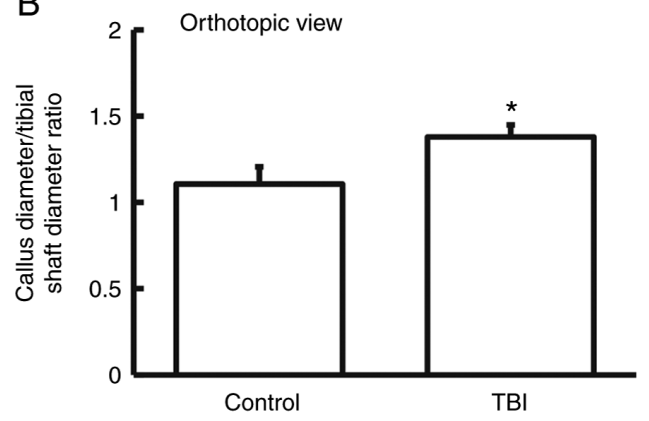

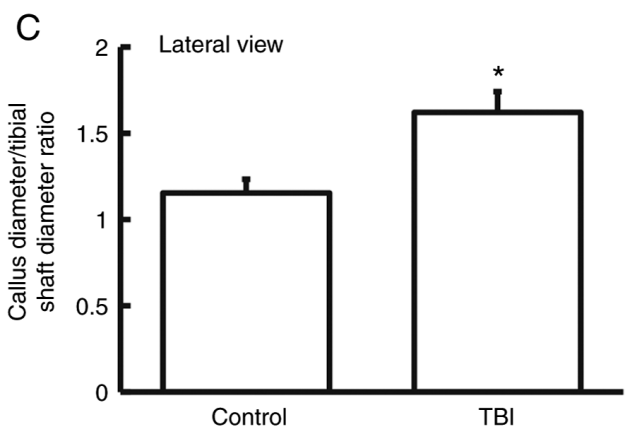

Figure 1. Comparison of fracture healing time and the ratio of callus diameter to tibial shaft diameter between tibial fracture patients with TBI and those without TBI. (A) Fracture healing time in days. The ratio of callus diameter to tibial shaft diameter in (B) orthotopic view and (C) lateral view. TBI, traumatic brain injury. ${ }^{*} \mathrm{P}<0.05$ compared vs. control group.

of the function of miRNAs (20). To predict genes that may regulate SPP1, miRanda was used. miR-433 was identified as a potential gene that could regulate SPP1 (Fig. 5A). Dual luciferase reporter assay showed that the luciferase intensity of cells co-transfected with agomiR-433 and pMIR-REPORT-wild-type luciferase reporter plasmids was significantly lower than that in the NC group $(\mathrm{P}<0.01 ; \mathrm{n}=3)$. By contrast, the luciferase intensity of cells co-transfected with agomiR-433 and pMIR-REPORT-mutant luciferase reporter plasmids was not significantly different from that in the NC group ( $\mathrm{P}>0.05$; $=3$; Fig. 5B). After transfection with agomiR-433, the expression of miR-433 in hFOB1.19 cells was significantly higher than that of cells transfected with agomiR-NC $(\mathrm{P}<0.01 ; \mathrm{n}=3$; Fig. 5C). Moreover, expression of SPP1 mRNA and protein in hFOB1.19 cells transfected with agomiR-433 was significantly lower than that in hFOB1.19 cells transfected with agomiR-NC $(\mathrm{P}<0.05 ; \mathrm{n}=3$; Fig. 5D and $\mathrm{E})$. These results suggest that miR-433 regulates the expression of SPP1 mRNA and protein by directly binding with the 3'-UTR of SPP1 mRNA.

\section{Discussion}

In the present study, the expression of SPP1 in callus, heterotopic ossification tissue and blood of patients with tibial fracture was examined after craniocerebral injury, the expression of miR-433 upstream of SPP1 measured in various specimens and the regulation of SPP1 by miR-433 in osteoblasts assessed in cells. The mechanism of miR-433 regulation of SPP1 in the process of tibial fracture recovery after craniocerebral injury was also preliminarily discussed.

Fracture healing is a complex process with histological and biochemical changes and it is affected by many factors such as patients' general condition, fracture type and severity, blood supply and mechanics (21). The natural process of fracture healing is generally divided into three connected parts: i) The initial stage of hematoma and inflammation, ii) the callus formation stage; and iii) the bone plate formation and remoulding stage (21). Heterotopic ossification is an important secondary disease after fracture and occurs where a bone structure is formed outside of the bone system (22). Heterotopic ossification is characterized by the rapid formation of calcified bone in soft tissues, causing swelling and pain around joints, as well as joint movement disorders (22). The formation of heterotopic ossification occurs in response to a particular stimulus and the interaction between osteoblasts and the microenvironment (23).

SPP1 can promote adhesion of tumor cells and degradation of their extracellular matrix by binding with CD44 and integrin, thereby inhibiting tumor cell apoptosis (24). In addition, SPP1 promotes angiogenesis and inhibits immune functions of the body, leading to tumor invasion and metastasis (25). SPP1 is secreted by osteoblasts, osteocytes and osteoclasts and plays important roles in the mineralization and absorption of bone matrix. SPP1 is abundant in areas of endochondral ossification and intramembranous ossification and can be observed in the cytoplasm of osteoblasts and osteoblasts in woven bones. SPP1 protein contains a region rich in aspartic acid and it can combine with hydroxyapatite in tissues through this region to exert its roles (26-28). After the initiation of bone matrix mineralization, the level of SPP1 in osteoblasts begins to increase, suggesting that SPP1 exerts its functions in the termination of mineralization of osteoblasts (29). The present study results suggested that the expression of SPP1 in callus, heterotopic ossification tissue and plasma of patients with tibial fracture and craniocerebral 
Table I. Heterotopic ossification status.

\begin{tabular}{lccc}
\hline Groups & $\begin{array}{c}\text { With heterotopic } \\
\text { ossification }\end{array}$ & $\begin{array}{c}\text { Without heterotopic } \\
\text { ossification }\end{array}$ & $\begin{array}{c}\text { Incidence of } \\
\text { heterotopic ossification }\end{array}$ \\
\hline Control & 3 & 23 & $11.5 \%$ \\
TBI & 6 & 20 & $23.0 \% \mathrm{a}^{\mathrm{a}}$ \\
\hline
\end{tabular}

${ }^{\mathrm{a}} \mathrm{P}<0.05$ vs. control group.

A

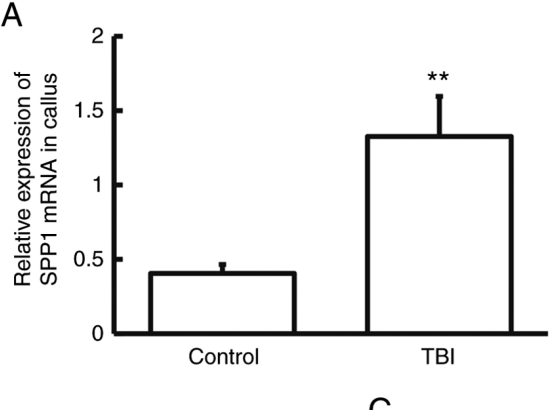

C
B

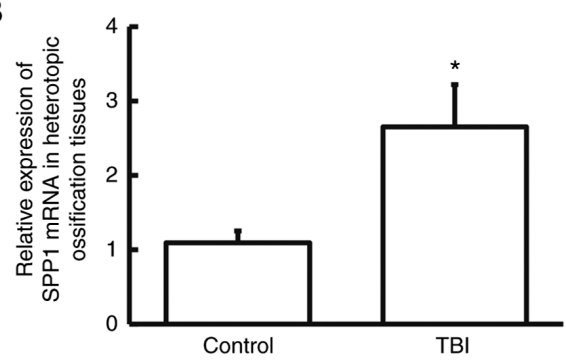

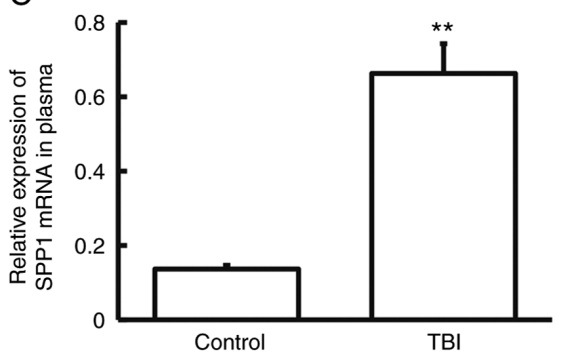

Figure 2. Expression of SPP1 mRNA in (A) callus, (B) heterotopic ossification tissues and (C) plasma from patients. Reverse transcription-quantitative PCR was used to determine mRNA expression levels. SPP1, osteopontin; TBI, traumatic brain injury. ${ }^{*} \mathrm{P}<0.05,{ }^{* * *} \mathrm{P}<0.01$ vs. control group.

A

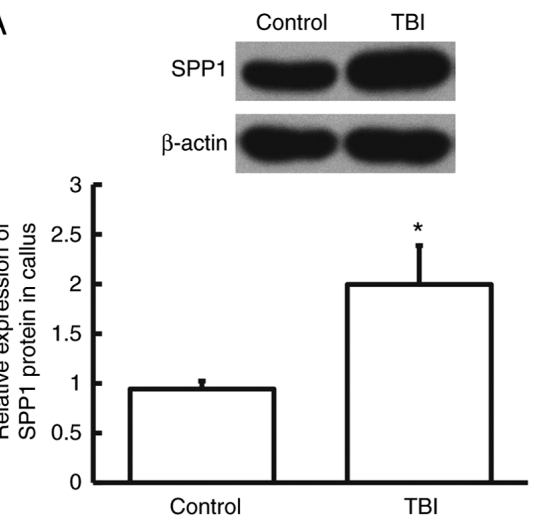

B

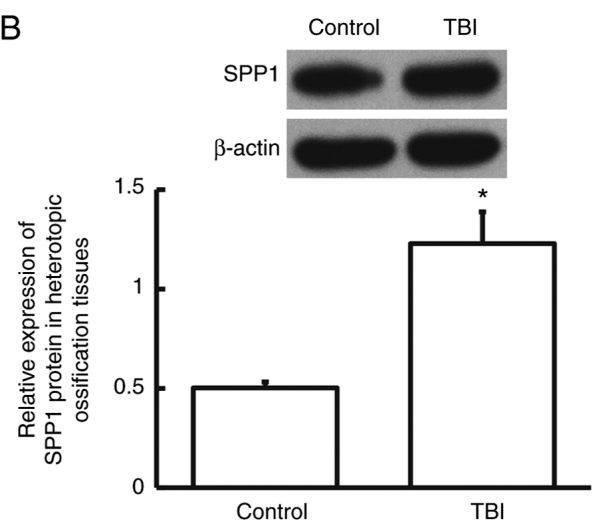

C

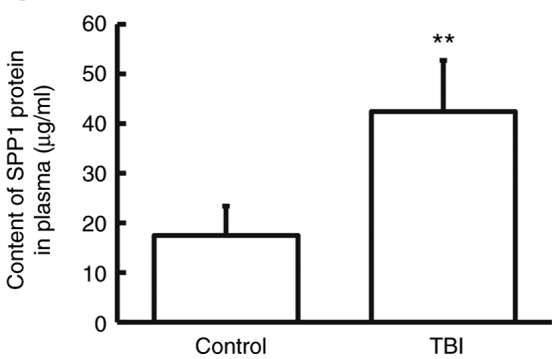

Figure 3. Expression of SPP1 protein in (A) callus, (B) heterotopic ossification tissues and (C) plasma from patients. Western blotting was used to determine protein expression in callus and heterotopic ossification tissues and ELISA was performed to measure protein content in plasma. SPP1, osteopontin; TBI, traumatic brain injury ${ }^{*} \mathrm{P}<0.05,{ }^{* *} \mathrm{P}<0.01$ vs. control group. 

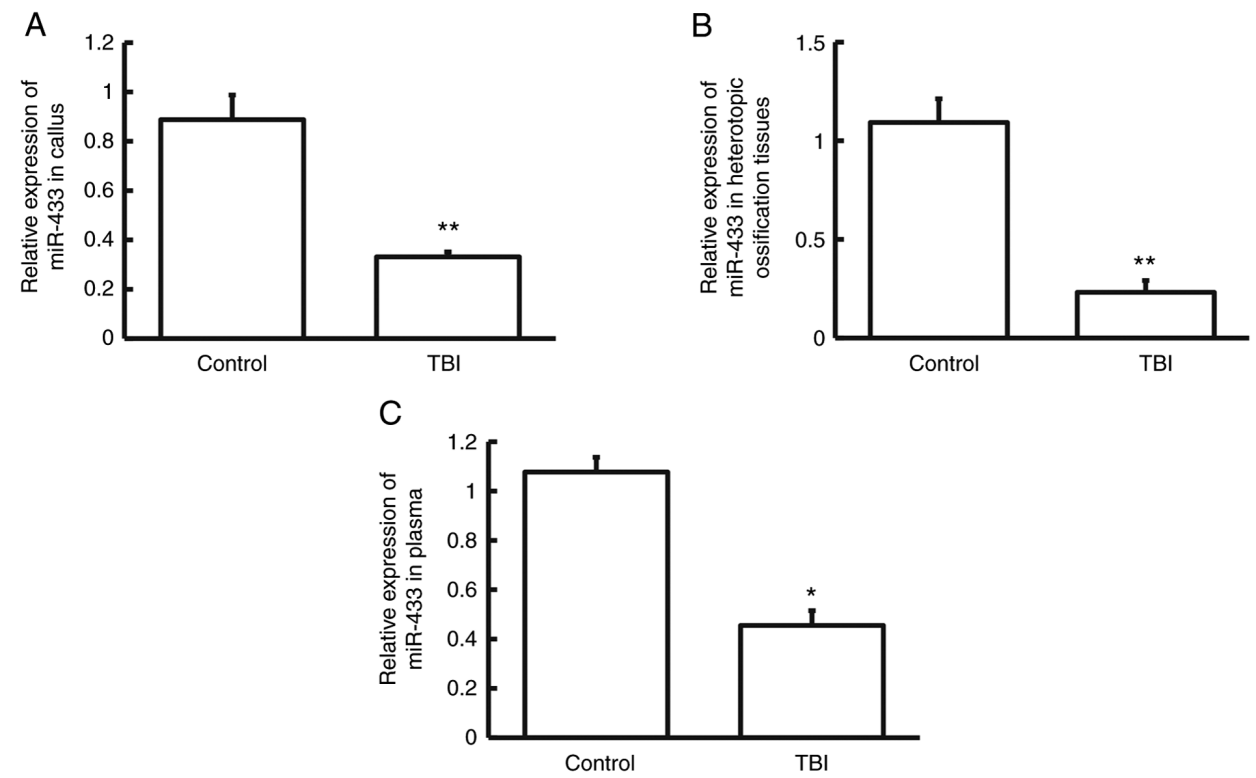

Figure 4. Expression of miR-433 in (A) callus, (B) heterotopic ossification tissues and (C) plasma from patients. Reverse transcription-quantitative PCR was used to determine miR-433 expression. miR, microRNA; TBI, traumatic brain injury ${ }^{*} \mathrm{P}<0.05,{ }^{* * *} \mathrm{P}<0.01$ vs. control group.
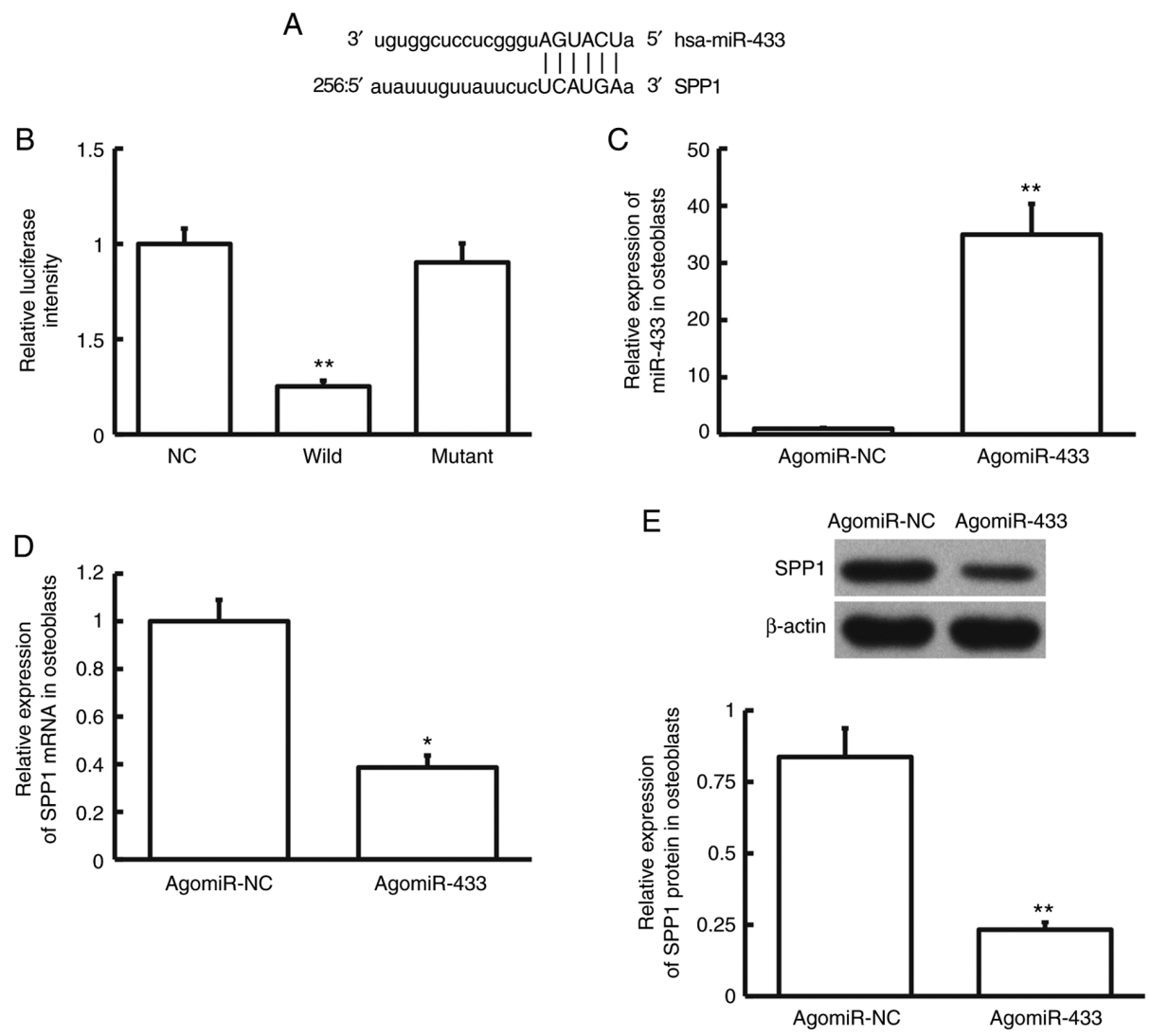

Figure 5. Effect of miR-433 overexpression on the expression of SPP1.(A) Bioinformatics prediction of direct interaction between miR-433 and the 3'-untranslated region of SPP1 mRNA. miRanda (http://www.microma.org/rnicroma/home.do) was used to predict genes that might regulate SPP1. (B) Identification of the interaction between miR-433 and SPP1 mRNA by dual luciferase reporter assay. (C) Expression of miR-433 in hFOB1.19 cells transfected with agomiR-433 or agomiR-NC. (D) Expression of SPP1 mRNA in hFOB1.19 cells transfected with agomiR-433 or agomiR-NC. (E) Expression of SPP1 protein in hFOB1.19 cells transfected with agomiR-433 or agomiR-NC. SPP1, osteopontin; miR, microRNA; NC, negative control; TBI, traumatic brain injury. "P<0.05 ** $\mathrm{P}<0.01$ compared with the agomiR-NC group.

injury was significantly higher than that of patients with simple tibial fracture, suggesting that the expression of SPP1 might be affected by craniocerebral injury. However, there was no significant difference in healing time between the two groups of patients, suggesting that SPP1 might not be related to the healing of patients. 
Endogenous, small, noncoding miRNAs in cells may cleave SPP1 mRNA and inhibit its translation (30). In this manner miRNAs promote up-regulation or down-regulation of mRNA expression to mediate the activity of protein-coding genes, playing important roles in the emergence and progression of diseases $(31,32)$. Using bioinformatics prediction, it was hypothesized that miR-433 was closely related to SPP1 and could be an upstream miRNA that regulated SPP1. miR-433 is a gene that has received increasing attention. Studies show that miR-433 may be a new target for tumor prevention, diagnosis and treatment $(33,34)$. miR-433 inhibits the invasion and migration of ovarian cancer cells by targeting the expression of Notch1 (35). In addition, miR-433 suppresses the proliferation, invasion and migration of glioma cells by inhibiting the expression of cAMP-response element binding protein (17). It has also been reported that miR-433 is related to the occurrence and progress of gastric cancer, liver cancer and myeloproliferative diseases (36-38). Yang et al (36) and Guo et al (37) indicated that $\mathrm{CpG}$ islands in the upstream promoter region of miR-433 were hypermethylated and that miR-433 expression was induced by 5-azacytidine, a DNA methyltransferase inhibitor. MicroRNA-433-3p promotes osteoblast differentiation through targeting Dickkopf WNT signaling pathway inhibitor 1 (39) or mediates estrogen related receptor- $\gamma$-suppressed osteoblast differentiation via direct targeting of Runt-related transcription factor 2 mRNA in C3H10T1/2 cells (40). In addition, miR-433 dampens glucocorticoid receptor signaling, impacting circadian rhythm and osteoblastic gene expression (41). miR-433 is also associated with a new form of dominant X-linked chondrodysplasia, suggesting that it has connections with bone-related diseases (42). In the present study, miR-433 expression in patients with TBI was lower than that in patients with simple tibial fracture. In consideration of our previous results regarding the expression of SPP1 mRNA and protein, it was hypothesized that the up-regulation of SPP1 could be caused by the abnormal down-regulation of miR-433. To identify direct binding between miR-433 and SPP1 mRNA a dual luciferase reporter assay was carried out. The result indicated that miR-433 was able to directly bind to the 3'-UTR of SPP1 mRNA to regulate the expression of SPP1. Moreover, human osteoblast line hFOB1.19 was transfected with agomiR-433 The results suggested that up-regulation of miR-433 inhibited SPP1 expression in osteoblasts, indicating a potential regulatory relationship between the two molecules in patients with tibial fracture and TBI.

The injury and healing of fractures involves the cooperation between multiple signaling pathways and the participation of many kinds of cells. For example, bone marrow mesenchymal stem cells promote tibial fracture healing in rabbits through JAK-STAT signaling pathway (43). Hyperhomocysteinemia inhibits tibial fracture healing in rats through PI3K/AKT signaling pathway (44). In addition, Qiao et al (45) report that intermittent hypoxia training and remote ischemic preconditioning significantly enhance fracture healing; however, intermittent hypoxia training exhibited superior bone formation and healing effects compared with remote ischemic preconditioning, suggesting that the interaction of multiple signal pathways and various physiological conditions in the human body have an impact on the condition of the fracture.

Due to practical limitations, it was not possible to match the patient's injuries precisely and individual differences in this study are larger than desirable. Therefore, future work is planned to continue to expand the number of cases as a follow-up study, in addition to the study of cell signaling pathway in order to gather more conclusive evidence for the findings of the present study.

In conclusion, the present study demonstrates that miR-433 expression in patients with tibial fracture and TBI is significantly lower than in patients with simple tibial fractures. As miR-433 directly targets SPP1 to regulate its expression, the expression of SPP1 mRNA is enhanced, leading to increased SPP1 protein expression in bone tissues and blood. This may play a biological role in the healing of tibial fractures.

\section{Acknowledgements}

Not applicable.

\section{Funding}

This work was supported by a grant from the Hospital-level Science and Technology Development Plan Project Fund of Zhangqiu District People's Hospital of Jinan City (grant no. 2018-17).

\section{Availability of data and materials}

The datasets used and/or analyzed during the current study are available from the corresponding author on reasonable request.

\section{Authors' contributions}

$\mathrm{ZH}$ and ML contributed to the design of the study. ZH, FS, YC, $\mathrm{XD}$ and BZ performed the experiments. ZH and FS analyzed the data. ZH, FS and ML interpreted results and prepared the manuscript. All authors have read and approved the final manuscript. ZH, FS, YC and XD confirm the authenticity of all the raw data.

\section{Ethics approval and consent to participate}

All procedures performed in the current study were approved by the Ethics Committee of Jinan Zhangqiu District People's Hospital. Written informed consent was obtained from all patients or their families.

\section{Patient consent for publication}

Not applicable.

\section{Competing interests}

The authors declare that they have no competing interests.

\section{References}

1. Li Z, Zhao J, Luo W, Li K, Lei S and Wang Y: Nrp-1 expression in healing process of traumatic brain injury combined with tibial fracture. Zhong Nan Da Xue Xue Bao Yi Xue Ban 42: 154-160, 2017 (In Chinese).

2. Kobylecki C, Glasse H, Amin J, Gregson CL, Lyell V and Henderson EJ: Fracture risk assessment in atypical parkinsonian syndromes. Mov Disord Clin Pract 8: 385-389, 2021. 
3. Brady RD, Grills BL, Church JE, Walsh NC, McDonald AC, Agoston DV, Sun M, O'Brien TJ, Shultz SR and McDonald SJ: Closed head experimental traumatic brain injury increases size and bone volume of callus in mice with concomitant tibial fracture. Sci Rep 6: 34491, 2016.

4. Jodoin M, Rouleau DM, Therrien E, Chauny JM, Sandman E, Larson-Dupuis C, Leduc S, Gosselin N and De Beaumont L: Investigating the incidence and magnitude of heterotopic ossification with and without joints involvement in patients with a limb fracture and mild traumatic brain injury. Bone Rep 11: 100222, 2019.

5. Boes M, Kain M, Kakar S, Nicholls F, Cullinane D, Gerstenfeld L, Einhorn TA and Tornetta P III: Osteogenic effects of traumatic brain injury on experimental fracture-healing. J Bone Joint Surg Am 88: 738-743, 2006.

6. Pang X, Gong K, Zhang X, Wu S, Cui Y and Qian BZ: Osteopontin as a multifaceted driver of bone metastasis and drug resistance. Pharmacol Res 144: 235-244, 2019.

7. Chen G, Zhang X, Li R, Fang L, Niu X, Zheng Y, He D, Xu R and Zhang JZ: Role of osteopontin in synovial Th17 differentiation in rheumatoid arthritis. Arthritis Rheum 62: 2900-2908, 2010

8. Gao SG, Li KH, Zeng KB, Tu M, Xu M and Lei GH: Elevated osteopontin level of synovial fluid and articular cartilage is associated with disease severity in knee osteoarthritis patients. Osteoarthritis Cartilage 18: 82-87, 2010.

9. Gattorno M, Gregorio A, Ferlito F, Gerloni V, Parafioriti A, Felici E, Sala E, Gambini C, Picco P and Martini A: Synovial expression of osteopontin correlates with angiogenesis in juvenile idiopathic arthritis. Rheumatology (Oxford) 43: 1091-1096, 2004.

10. Song SZ, Lin S, Liu JN, Zhang MB, Du YT, Zhang DD, $\mathrm{Xu}$ WH and Wang HB: Targeting of SPP1 by microRNA-340 inhibits gastric cancer cell epithelial-mesenchymal transition through inhibition of the PI3K/AKT signaling pathway. J Cell Physiol 234: 18587-18601, 2019.

11. Yu H, Sun H, Wang Z and Liu Y: MicroRNA let-7a up-regulates OPN expression in a mouse model of allergic rhinitis. J Laryngol Otol 131: 955-960, 2017.

12. Liu Y, Qian K, Li C, Ma Y and Chen X: Roles of microRNA-539 and osteopontin in rheumatoid arthritis. Exp Ther Med 15: 2681-2687, 2018

13. Jiang K, Teng GD and Chen YQ: MicroRNA-23 suppresses osteogenic differentiation of human bone marrow mesenchymal stem cells by targeting the MEF2C-mediated MAPK signaling pathway. J Gene Med 22: e3216, 2020.

14. Tao L, Bei Y, Chen P, Lei Z, Fu S, Zhang H, Xu J, Che L, Chen X, Sluijter JP, et al: Crucial role of miR-433 in regulating cardiac fibrosis. Theranostics 6: 2068-2083, 2016.

15. Zhang T, Jiang K, Zhu X, Zhao G, Wu H, Deng G and Qiu C: miR-433 inhibits breast cancer cell growth via the MAPK signaling pathway by targeting Rapla. Int J Biol Sci 14: 622-632, 2018.

16. Shi Q, Wang Y, Mu Y, Wang X and Fan Q: MiR-433-3p inhibits proliferation and invasion of esophageal squamous cell carcinoma by targeting GRB2. Cell Physiol Biochem 46: 2187-2196, 2018.

17. Sun S, Wang X, Xu X, Di H, Du J, Xu B, Wang Q and Wang J: MiR-433-3p suppresses cell growth and enhances chemosensitivity by targeting CREB in human glioma. Oncotarget 8: 5057-5068, 2017.

18. Rolfs F, Piersma SR, Dias MP, Jonkers J and Jimenez CR: Feasibility of phosphoproteomics on leftover samples after RNA extraction with guanidinium thiocyanate. Mol Cell Proteomics 20: $100078,2021$.

19. Livak KJ and Schmittgen TD: Analysis of relative gene expression data using real-time quantitative PCR and the 2(-Delta Delta C(T)) method. Methods 25: 402-408, 2001.

20. Zhao D, Chen $\mathrm{H}$ and Wang B: Assessing the regulatory functions of LncRNA SNHG11 in gastric cancer cell proliferation and migration. Front Cell Dev Biol 9: 620476, 2021.

21. Einhorn TA and Gerstenfeld LC: Fracture healing: Mechanisms and interventions. Nat Rev Rheumatol 11: 45-54, 2015.

22. Dey D, Wheatley BM, Cholok D, Agarwal S, Yu PB, Levi B and Davis TA: The traumatic bone: Trauma-induced heterotopic ossification. Transl Res 186: 95-111, 2017.

23. Micha D, Voermans E, Eekhoff ME, van Essen HW, Zandieh-Doulabi B, Netelenbos C, Rustemeyer T, Sistermans EA, Pals $\mathrm{G}$ and Bravenboer N: Inhibition of TGF $\beta$ signaling decreases osteogenic differentiation of fibrodysplasia ossificans progressiva fibroblasts in a novel in vitro model of the disease. Bone 84 169-180, 2016

24. Lin YH and Yang-Yen HF: The osteopontin-CD44 survival signal involves activation of the phosphatidylinositol 3-kinase/Akt signaling pathway. J Biol Chem 276: 46024-46030, 2001.
25. Wang KX and Denhardt DT: Osteopontin: Role in immune regulation and stress responses. Cytokine Growth Factor Rev 19: 333-345, 2008

26. Shao H, Wu R, Cao L, Gu H and Chai F: Trelagliptin stimulates osteoblastic differentiation by increasing runt-related transcription factor 2 (RUNX2): A therapeutic implication in osteoporosis Bioengineered 12: 960-968, 2021.

27. Wang J, Gao Z and Gao P: MiR-133b modulates the osteoblast differentiation to prevent osteoporosis via targeting GNB4. Biochem Genet, Mar 9, 2021 (Online ahead of print).

28. He HP and Gu S: The PPAR- $\gamma /$ SFRP5/Wnt/ $\beta$-catenin signal axis regulates the dexamethasone-induced osteoporosis. Cytokine 143: 155488, 2021

29. Foster BL, Ao M, Salmon CR, Chavez MB, Kolli TN, Tran AB, Chu EY, Kantovitz KR, Yadav M, Narisawa S, et al: Osteopontin regulates dentin and alveolar bone development and mineralization. Bone 107: 196-207, 2018.

30. Ma C, Wei F, Xia H, Liu H, Dong X, Zhang Y, Luo Q, Liu Y and Li Y: MicroRNA-10b mediates TGF- $\beta 1$-regulated glioblastoma proliferation, migration and epithelial-mesenchymal transition. Int J Oncol 50: 1739-1748, 2017.

31. Zhao X, Mohan R, Özcan S and Tang X: MicroRNA-30d induces insulin transcription factor MafA and insulin production by targeting mitogen-activated protein 4 kinase 4 (MAP4K4) in pancreatic $\beta$-cells. J Biol Chem 287: 31155-31164, 2012.

32. Chen K and Rajewsky N: The evolution of gene regulation by transcription factors and microRNAs. Nat Rev Genet 8: 93-103, 2007.

33. Li J, Chen M and Yu B: miR-433 suppresses tumor progression via Smad2 in non-small cell lung cancer. Pathol Res Pract 215: 152591, 2019.

34. Zhao YF, Li MX, Chang GZ and He XH: ERK on apoptosis of gastric cancer cells induced by microRNA-433. Zhonghua $\mathrm{Yi}_{1}$ Xue Za Zhi 98: 3954-3957, 2018 (In Chinese).

35. Liang T, Guo Q, Li L, Cheng Y, Ren C and Zhang G: MicroRNA-433 inhibits migration and invasion of ovarian cancer cells via targeting Notch1. Neoplasma 63: 696-704, 2016.

36. Yang Z, Tsuchiya $H$, Zhang $Y$, Hartnett ME and Wang L: MicroRNA-433 inhibits liver cancer cell migration by repressing the protein expression and function of cAMP response element-binding protein. J Biol Chem 288: 28893-28899, 2013.

37. Guo LH, Li H, Wang F, Yu J and He JS: The tumor suppressor roles of miR-433 and miR-127 in gastric cancer. Int J Mol Sci 14: 14171-14184, 2013.

38. Lin X, Rice KL, Buzzai M, Hexner E, Costa FF, Kilpivaara O, Mullally A, Soares MB, Ebert BL, Levine R and Licht JD: miR-433 is aberrantly expressed in myeloproliferative neoplasms and suppresses hematopoietic cell growth and differentiation. Leukemia 27: 344-352, 2013.

39. Tang X, Lin J, Wang G and Lu J: MicroRNA-433-3p promotes osteoblast differentiation through targeting DKK1 expression. PLoS One 12: e0179860, 2017.

40. Kim EJ, Kang IH, Lee JW, Jang WG and Koh JT: MiR-433 mediates ERR $\gamma$-suppressed osteoblast differentiation via direct targeting to Runx2 mRNA in C3H10T1/2 cells. Life Sci 92: $562-568,2013$

41. Smith SS, Dole NS, Franceschetti T, Hrdlicka HC and Delany AM: MicroRNA-433 dampens glucocorticoid receptor signaling, impacting circadian rhythm and osteoblastic gene expression. J Biol Chem 291: 21717-21728, 2016.

42. Simon D, Laloo B, Barillot M, Barnetche T, Blanchard C, Rooryck C, Marche M, Burgelin I, Coupry I, Chassaing N, et al: A mutation in the 3'-UTR of the HDAC6 gene abolishing the post-transcriptional regulation mediated by hsa-miR-433 is linked to a new form of dominant X-linked chondrodysplasia. Hum Mol Genet 19: 2015-2027, 2010.

43. Wang P and Zhang Z: Bone marrow-derived mesenchymal stem cells promote healing of rabbit tibial fractures via JAK-STAT signaling pathway. Exp Ther Med 19: 2310-2316, 2020.

44. Liu S, Huang Y, Tian S, Zhang W, Xu Y and Ge J: Hyperhomocysteinemia inhibits tibial fracture healing in rats through PI3K/AKT signaling pathway. Exp Ther Med 19: 2083-2088, 2020

45. Qiao J, Zhou M, Li Z, Ren J, Gao G, Cao G, Shen H and Lu S: Comparison of remote ischemic preconditioning and intermittent hypoxia training in fracture healing. Mol Med Rep 19: 1867-1874, 2019.

This work is licensed under a Creative Commons Attribution-NonCommercial-NoDerivatives 4.0 International (CC BY-NC-ND 4.0) License. 